\title{
Mechanisms controlling volume change of saturated clays and the role of the effective stress concept
}

\author{
SRIDHARAN, A. and VENKATAPPA RAO, G. (1973). Géotechnique 23, No. 3, 359-382. \\ Discussion by De (1974). Géotechnique 24, No. 3, 447. \\ Discussion by Foster (1974). Géotechnique 24, No. 3, 448.
}

\section{Authors' reply to De and to Foster}

Foster has raised a number of useful points. Table 1 presents information regarding $\mathrm{pH}$, cation exchange capacities, and types of cation associating with the clay minerals. Although it is true that associating cations are especially relevant to the nature of the adsorption phase, the primary purpose was to bring out the important role of the type of clay mineral itself in the overall volume change behaviour. It is true that the double-layer theory was developed for dilute suspensions; however, it forms a useful tool to make a qualitative study of the volume change behaviour of clays.

We fully agree that there is a variation in fabric at $8 \mathrm{t} / \mathrm{ft}^{2}$ (Figs 2(a) and 2(b)) with the systems possessing different fluids. This is attributed to the differences in void ratio caused by the different pore-fluids. It is also agreed that there is difference in the fabric between the two series (i.e. series on compacted system and series on remoulded system). It was the aim of the Paper to bring out the same phenomenon by two altogether different methods of introducing a different fluid into the system. It was not our intention to keep the fabric the same.

Foster feels that factors other than dielectric constant and fabric may be responsible for reducing appreciably the shear strength at low values of dielectric constant (Figs 6(a) and 6(b)). While such a possibility cannot be denied, the conclusion that could be drawn from the present investigation was only with respect to the dielectric constant.

We tend to agree that the term 'flocculation' is normally associated with 'dilute suspension'. Our intention in using the word 'flocculation' was to indicate the possibility of formation of relatively open structure in relation to that of the original fabric under the same external load with the water as pore-fluid. In a saturated system the increase in volume, especially with the change of low dielectric fluid, could possibly be attributed to the 'flocculation' as meant here rather than 'double layer swelling'.

The writers appreciate the difficulties and complexities of replacing one fluid with another as discussed by De. They have attempted to do this in their investigation and feel that the 'indirect' method is much superior to the 'direct' one and the procedure is fairly successful if the replacing fluid has the higher dielectric constant. Their experience with regard to the replacement of water is that it is only partially successful, especially with highly plastic clays.

Table 1. Base exchange capacities and $\mathrm{pH}$ value of the soils

\begin{tabular}{|c|c|c|c|}
\hline Property & Kaolinite & Monlmorillonite & $\begin{array}{c}\text { Black cotton } \\
\text { soil }\end{array}$ \\
\hline $\begin{array}{c}\text { Base exchange capacity, } \\
\mathrm{m} \mathrm{ed} / 100 \mathrm{gm}\end{array}$ & $8 \cdot 1$ & $74 \cdot 2$ & $35 \cdot 5$ \\
\hline Exchangeable potassium, & 0 & 0 & $3 \cdot 0$ \\
\hline Exchangeable sodium, \% & $18 \cdot 2$ & $97 \cdot 8$ & $63 \cdot 1$ \\
\hline Exchangeable calcium, $\%$ & $81 \cdot 8$ & $2 \cdot 0$ & $29 \cdot 2$ \\
\hline $\begin{array}{l}\text { Exchangeable magnesium, } \\
\%\end{array}$ & 0 & $0 \cdot 2$ & $4 \cdot 7$ \\
\hline $\mathrm{pH}^{\circ}$ & $6 \cdot 5$ & $9 \cdot 75$ & $9 \cdot 5$ \\
\hline
\end{tabular}

